\title{
Results of the surgical treatment in children with Chiari malformation type I
}

\author{
Paweł Jarski $^{1}$ - Mikołaj Zimny ${ }^{1} \cdot$ Michał Linart $^{1} \cdot$ Zofia Kozłowska $^{1} \cdot$ Marek Mandera $^{1}$ (D)
}

Received: 9 May 2019 / Accepted: 30 May 2019 / Published online: 17 June 2019

(C) The Author(s) 2019

\begin{abstract}
Purpose Our study aimed to evaluate the quality of life of the patients operated due to Chiari malformation type 1 (CM-1) in the Department of Pediatric Neurosurgery, Medical University of Silesia in Katowice.

Methods We performed a retrospective analysis of 11 patients diagnosed with CM-1 who were treated in our center in the years 2007 to 2016. There were 6 female and 5 male individuals. Short-term evaluation of the outcome was based on comparison of the presenting symptoms and radiological images before and after the surgical treatment. Long-term follow-up was carried out using survey questionnaires based on the Chicago Chiari Outcome Scale (CCOS) devised originally by Aliaga et al.

Results Patients, based on their CCOS score were divided into three groups marked as "improved," "unchanged," and "worse," depending on a range of CCOS score: 13-16, 9-12, 4-8, respectively. The outcome of patients was as follows: 6 patients (55\%) were evaluated as improved, and $5(45 \%)$ as unchanged. No patient was classified as worse after surgery. Significant negative Spearman's correlation was found between the CCOS score and patients' age at the time of surgery $(R=-0.85, p=0.0009)$.

Conclusions The decision of whether to operate pediatric patients with CM-1 should be considered very carefully. In our department, the main indication for surgery was the occurrence of clinical symptoms. Our study revealed that in the symptomatic patients, surgery improves their quality of life measured with CCOS.
\end{abstract}

Keywords Chiari type 1 . Children · Surgical treatment · Quality of life · Chicago Chiari Outcome Scale

\section{Introduction}

Chiari malformation type $1(\mathrm{CM}-1)$ is a congenital disorder typically defined as a herniation of the cerebellar tonsils equal to or more than $5 \mathrm{~mm}$ below the foramen magnum into the spinal canal visible on MRI or CT scans $[1,4]$. CM-1 is more common among pediatric patients $(0.8-3.7 \%$ in children [13, $18,19]$ vs. $0.24-0.9 \%$ in adults $[15,18,21])$ and may be accompanied by syringomyelia $[9,20]$. Using tonsillar position as an only diagnostic criterium may lead to misdiagnoses as some patients with tonsillar herniation less than $5 \mathrm{~mm}$ may present with CM-1 symptoms $[1,8,17]$ and many patients with the low tonsillar position may be completely asymptomatic $[16,18,19]$.

Marek Mandera

mmandera@sum.edu.pl

1 Department of Pediatric Neurosurgery, Medical University of Silesia in Katowice, ul. Medykow 16, 40-752 Katowice, Poland
The most common symptoms caused by tonsillar herniation are headache, intramedullary syndrome, motor deficits, paresthesia, hyperreflexia in lower limbs, nystagmus, and gait disturbance. Surgical treatment is the only way to improve symptoms and prevent from a progression of the clinical manifestation [14]. The primary type of surgery performed is craniocervical decompression with or without additional procedures such as duraplasty and reconstruction of the cisterna magna, cerebellar tonsils' cauterization, and reconstruction of arachnoid and exploration of the 4 th ventricle $[3,10]$. The main aim of the surgical treatment is to improve cerebrospinal fluid circulation, reconstruct subarachnoid space, and reduce possible compression of the brainstem.

Our study aimed to evaluate the outcome of the patients treated due to CM-1 in our center.

We have conducted the retrospective analysis of the medical records of pediatric patients treated for CM-1 in the Department of Pediatric Neurosurgery in Katowice from 2007 to 2016. We identified 11 patients under the age of 18 (6 girls and 5 boys) diagnosed with CM-1, with or without any accompanying disorders - syringomyelia and hydrocephalus. 
Short-term evaluation (mean observation time was 35 months) of the outcome was based on clinical examination and radiological images (MRI or CT scan). Long-term follow-up included physical examination, MRI or CT scan, and survey questionnaires based on the Chicago Chiari Outcome Scale (CCOS) designed originally by Aliaga et al. [2].

\section{What symptoms are considered typical?}

The most common symptom in our group was headache. In 7 cases, it was localized in the occipital region and 1 case in the temporal region. It was followed by gait disturbance ( 5 cases) and neck pain (4 patients). Three patients presented with positive Romberg's test and also 3 individuals with dysphagia. The most common associated radiological sign was syringomyelia (6 patients), mostly in the cervical region.

\section{Criteria for surgical indications}

Inclusion criteria for surgical intervention were as follows: cerebellar tonsils' herniation more than $5 \mathrm{~mm}$ below the foramen magnum in MRI study and simultaneous occurrence of clinical symptoms that disturbed patients' participation in their daily duties or routines. The evaluation of the tonsillar herniation depth was managed by measuring the length of the cerebellar tonsils beneath the line drawn between the inner margins of the foramen magnum. Asymptomatic cerebellar tonsils' herniation was not an indication for surgery.

\section{Type of surgery commonly used}

The most common surgical procedure was bony decompression of foramen magnum ( 8 cases) and bony decompression with additional duraplasty and reconstruction of the cisterna magna ( 2 cases). We usually used to perform small posterior fossa craniectomy and laminectomy $\mathrm{C} 1$. One patient underwent endoscopic third ventriculostomy to treat hydrocephalus at first.

\section{When the result is considered good?}

In the short-term follow-up, the outcome was considered good when patients or their parents (caregivers) reported an improvement of symptoms. Good long-term outcome was considered if the patient was evaluated as "improved" according to $\mathrm{CCOS}$ score.

Due to a small study group, data and basic descriptive statistics were summarized and analyzed with the use of Microsoft Office 2016, Excel software, and Statistica 13.0 (StatSoft).

\section{Presentation of the series}

Our group consisted of 11 patients, 6 females and 5 males. The most common associated condition was syringomyelia (6 patients, 55\%), most commonly located in the cervical segments. The median age of our patients was 9 years (IQR $=2-13$ ). Median time from admission to surgery was 1 day (IQR = $1-1)$, and the median total length of stay in hospital was 8 days $(\mathrm{IQR}=6-9)$. The most common method of treatment was bony decompression (suboccipital craniectomy together with laminectomy $\mathrm{C} 1$ ) performed without or with duraplasty and reconstruction of the cisterna magna ( 8 and 2 patients, respectively). None of the patients underwent reoperation. The average time that elapsed from surgery to assessment using CCOS was 50.9 months (ranged 8-110 months).

According to the authors of CCOS, patients should be assessed not earlier than 12 months after surgery due to the risk of recurrence of certain symptoms [2]. Two of our patients were assessed 8 months after surgery, which can be perceived as a limitation of our study. Median CCOS was 13 (IQR $=11-15$, ranged 10-16). The patients were divided into three groups, described as improved, unchanged, or worse, with corresponding CCOS scores of 13-16, 9-12, and 4-8, respectively. Six patients were categorized as improved and 5 as unchanged. No one was evaluated as "worse" after surgery. Mean score in each category of the scale was as follows: pain $=3(\mathrm{IQR}=2-4)$, non-pain $=3$ $(\mathrm{IQR}=2-4)$, functionality $=3(\mathrm{IQR}=3-4)$, complications $=4$ $(\mathrm{IQR}=3-4)$. Percentage distribution of scores in all CCOS categories is presented in Fig. 1.

We found significant negative Spearman's correlation between CCOS total score and age at surgery $(\mathrm{R}=-0.85, p=$ $0.0009)$ [Fig. 2]. The most common symptoms reported during follow-up in the "pain category" were headache and balance disorders in the "non-pain category."

Incidence of CM-1 was estimated at $0.5-3.5 \%$ in MRI studies and about $0.62 \%$ in anatomical studies in the general population $[5,12,13]$. The presence of tonsillar ectopia itself is not an indication for the surgery. Only if clinical symptoms occur, the surgery may be considered. There are not many manuscripts that describe the effects of surgical treatment of CM-1 in a pediatric population, and there is no consensus on the optimal surgical technique. In our department, 8 patients underwent bony decompression without duraplasty, and 2 patients underwent laminectomy with duraplasty and reconstruction of the cisterna magna. One patient was initially treated with ETV due to hydrocephalus that coexisted with CM-1. According to CCOS, the symptoms of most patients improved after the surgical treatment in our study. We did note report worsening in any patient.

Chotai and Medhkour [6] noticed a significant overall improvement in $85 \%$ of operated patients during a mean followup period of 14.7 months (range 1-60 months). However, their study group analyzed the patients aged from 16 to 58 years. 


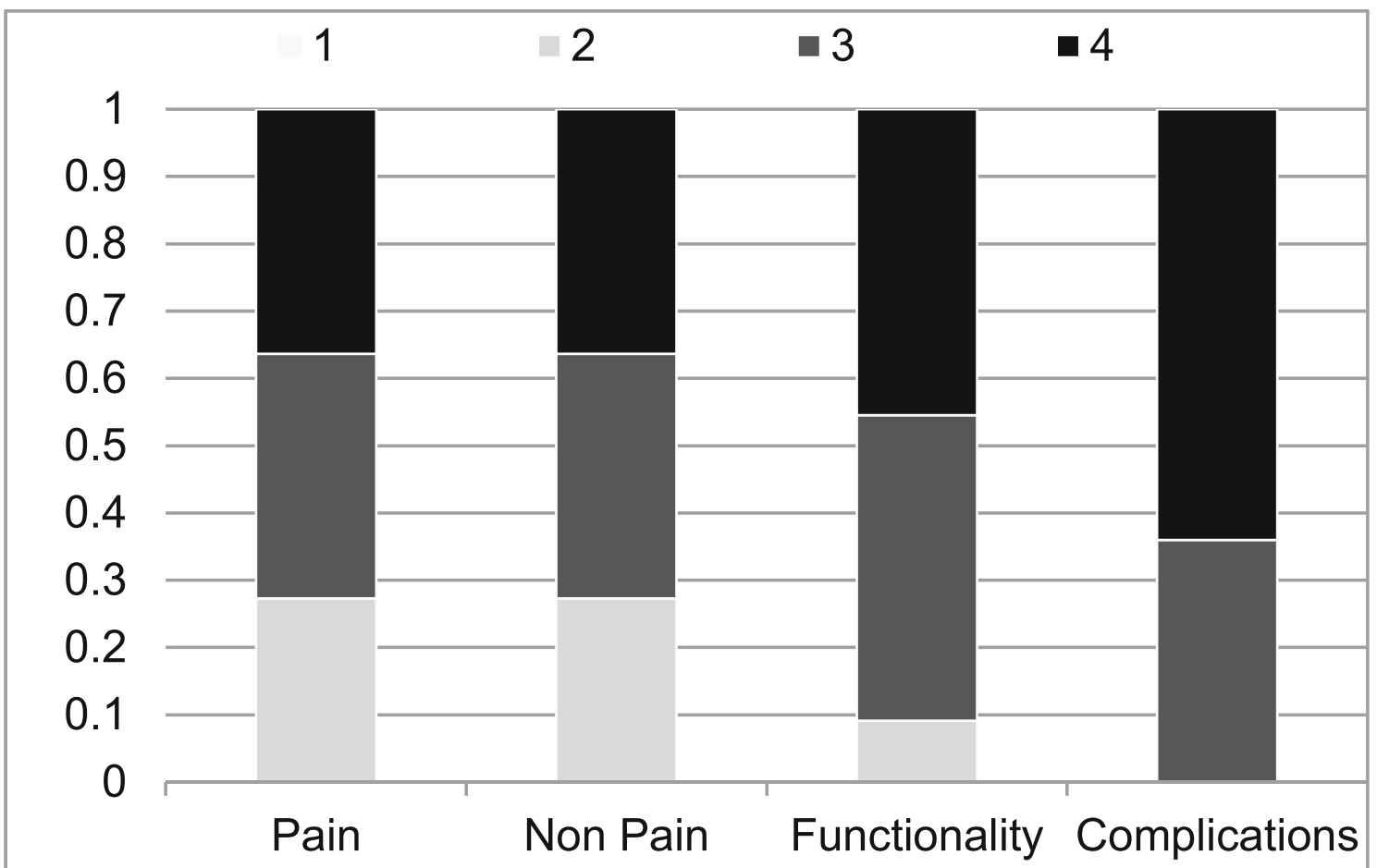

Fig. 1 Percentage distribution of scores in particular CCOS categories among the study group

Förander et al. in their review and meta-analysis [7] found that $96(23 \%)$ patients treated with bony decompression and duraplasty did not improve neurologically after the surgery. Also, 11 patients out of the total number of $51(22 \%)$ treated with bony decompression alone did not improve after surgery. It means that less than $25 \%$ of patients in both groups failed to improve after any surgery.

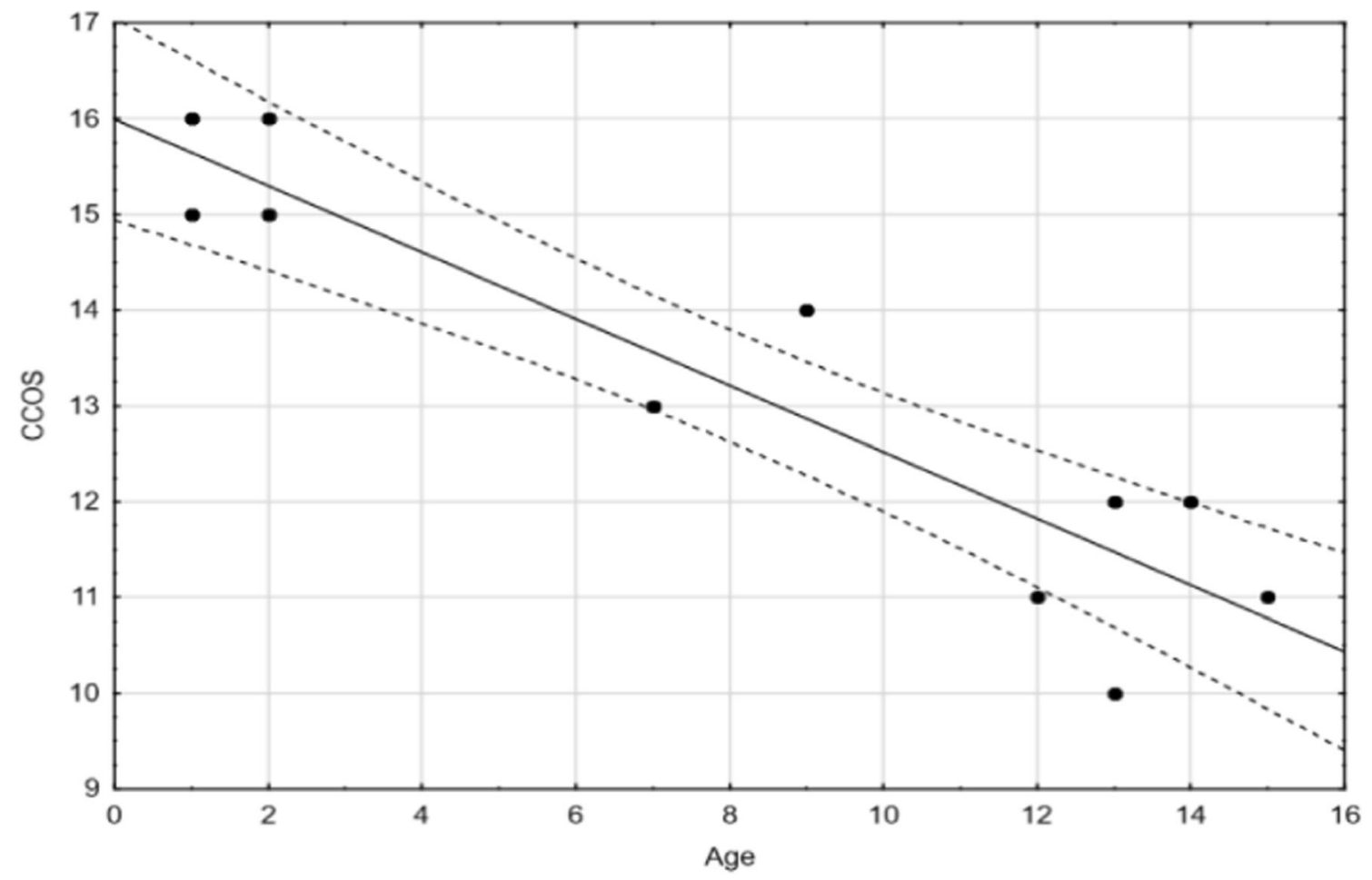

Fig. 2 Spearman's rank correlation between age and CCOS $(\mathrm{CI}=0.95)$ 
In another review of 18 articles carried out by Zhao et al., overall clinical improvement was noticed in almost $80 \%$ of patients, $14 \%$ of patients were stable, and in nearly $7 \%$ worsened after surgery [22].

Massimi et al. [11], in a very recent paper, presented results of treatment of 42 patients with CM-1. The mean follow-up was 11.3 years (ranged 5-15 years). They showed that symptoms disappeared completely in $76.5 \%$ of patients, and the next $21.5 \%$ of patients improved after the surgical intervention. Only 1 patient did not change after the surgery. All patients underwent suboccipital craniectomy. Additional C1 laminectomy was performed in $90 \%$ of cases and dural delamination in $50 \%$ of patients.

\section{Conclusion}

The decision of whether to operate pediatric patients with CM-1 should be considered very carefully. In our department, the main indication for surgery was the occurrence of clinical symptoms. Our study revealed that in the symptomatic patients, surgery improves their quality of life measured with CCOS.

\section{Compliance with ethical standards}

Conflict of interest The authors declare that they have no conflict of interest.

Open Access This article is distributed under the terms of the Creative Commons Attribution 4.0 International License (http:// creativecommons.org/licenses/by/4.0/), which permits unrestricted use, distribution, and reproduction in any medium, provided you give appropriate credit to the original author(s) and the source, provide a link to the Creative Commons license, and indicate if changes were made.

\section{References}

1. Aboulezz AO, Sartor K, Geyer CA, Gado MH (1985) Position of cerebellar tonsils in the normal population and in patients with Chiari malformation: a quantitative approach with MR imaging. J Comput Assist Tomogr 9:1033-1036

2. Aliaga L, Hekman KE, Yassari R, Straus D, Luther G, Chen J, Sampat A, Frim D (2012) A novel scoring system for assessing Chiari malformation type I treatment outcomes. Neurosurgery 70(3):656-665

3. Arnautovic A, Splavski B, Boop FA, Arnautovic KI (2015) Pediatric and adult Chiari malformation type I surgical series 1965-2013: a review of demographics, operative treatment, and outcomes. J Neurosurg Pediatr 15:161-177

4. Barkovich AJ, Wippold FJ, Sherman JL, Citrin CM (1986) Significance of cerebellar tonsillar position on MR. AJNR Am J Neuroradiol 7:795-799

5. Bejjani GK (2001) Definition of the adult Chiari malformation: a brief historical overview. Neurosurg Focus 11(1):E1
6. Chotai S, Medhkour A (2014) Surgical outcomes after posterior fossa decompression with and without duraplasty in Chiari malformation-I. Clin Neurol Neurosurg 125:182-188

7. Förander P, Sjåvik K, Solheim O, Riphagen I, Gulati S, Salvesen Ø, Jakola AS (2014) The case for duraplasty in adults undergoing posterior fossa decompression for Chiari-I malformation: a systematic review and meta-analysis of observational studies. Clin Neurol Neurosurg 125:58-64

8. Işik N, Elmaci I, Silav G, Celik M, Kalelioğlu M (2009) Chiari malformation type III and results of surgery: a clinical study: report of eight surgically treated cases and review of the literature. Pediatr Neurosurg 45:19-28

9. Isu T, Iwasaki Y, Akino M, Abe H (1990) Hydrosyringomyelia associated with a Chiari I malformation in children and adolescents. Neurosurgery 26:591-596 discussion: 596-597

10. Kunert P, Janowski M, Zakrzewska A, Marchel A (2009) Comparison of results between two different techniques of cranio-cervical decompression in patients with Chiari I malformation. Neurol Neurochir Pol 43(4):337-345

11. Massimi et al (2019) Bony decompression for Chiari malformation type I: long-term follow-up. Acta Neurochir Suppl 125:119-124

12. Meadows J, Guarnieri M, Miller K, Haroun R, Kraut M, Carson BS et al (2001) Type I Chiari malformation: a review of the literature. Neurosurg Q 11:220-229

13. Meadows J, Kraut M, Guarnieri M, Haroun RI, Carson BS (2000) Asymptomatic Chiari type I malformations identified on magnetic resonance imaging. J Neurosurg 92:920-926

14. Morina D, Petridis AK, Fritzsche FS, Ntoulias G, Scholz M (2013) Syringomyelia regression after shunting of a trapped fourth ventricle. Clin Pract 30;3(1):e 1

15. Morris Z, Whiteley WN, Longstreth WT Jr, Weber F, Lee YC, Tsushima $Y$ et al (2009) Incidental findings on brain magnetic resonance imaging: systematic review and meta-analysis. BMJ 339: b3016

16. Pomeraniec IJ, Ksendzovsky A, Awad AJ, Fezeu F, Jane JA Jr (2016) Natural and surgical history of Chiari malformation type I in the pediatric population. J Neurosurg Pediatr 17:343-352

17. Shehu B, Ismail N, Mahmud M, Hassan I (2006) Chiari I malformation: a missed diagnosis. Ann Afr Med 5:206-208

18. Smith BW, Strahle J, Bapuraj JR, Muraszko KM, Garton HJ, Maher CO (2013) Distribution of cerebellar tonsil position: implications for understanding Chiari malformation. J Neurosurg 119:812-819

19. Strahle J, Muraszko KM, Kapurch J, Bapuraj JR, Garton HJ, Maher CO (2011) Chiari malformation type I and syrinx in children undergoing magnetic resonance imaging. J Neurosurg Pediatr 8:205213

20. Tubbs RS, Smyth MD, Wellons JC 3rd, Oakes WJ (2004) Arachnoid veils and the Chiari I malformation. J Neurosurg 100(5 suppl pediatrics):465-467

21. Vernooij MW, Ikram MA, Tanghe HL, Vincent AJ, Hofman A, Krestin GP et al (2007) Incidental findings on brain MRI in the general population. N Engl J Med 357:1821-1828

22. Zhao J, Li M, Wang C, Meng W (2016) A systematic review of Chiari I malformation: techniques and outcomes. World Neurosurg $88: 7-14$

Publisher's note Springer Nature remains neutral with regard to jurisdictional claims in published maps and institutional affiliations. 